\title{
NOVAS OCORRÊNCIAS DE BRYOPHYTA (MUSGOS) PARA O ESTADO DO PARÁ, BRASIL.
}

\author{
Regina C. L. LISBOA ${ }^{1}$, Anna L. ILKIU-BORGES ${ }^{1}$
}

RESUMO - Com o objetivo de ampliar o conhecimento da brioflora e a distribuição geográfica das briófitas no Brasil, são apresentadas 11 espécies de musgos como novas ocorrências para o Estado do Pará. Duas espécies, Fissidens allenianus Brugg.-Nann. \& Pursell e Taxithelium portoricense Williams, são primeiras referências para o Brasil. Comentários morfológicos, taxonômicos e ecológicos e fotomicrografias, acompanham cada espécie.

Palavras-Chave : brioflora, musgos, novas ocorrências, Fitogeografia, Pará.

New Occurrences of Bryophyta (Mosses) for the State of Pará, Brazil.

SUMMARY - Eleven species of mosses are reported as new for the State of Pará, as a contribution to enlarge the knowledge about the bryoflora of this state. Fissidens allenianus Brugg.-Nann. \& Pursell and Taxithelium portoricense Williams are reported as new to Brazil. Morphological, taxonomic and ecological comments are given for each species, along with photomicrographs.

Key-Words: bryoflora; mosses; new occurrences; Phytogeography; Pará.

\section{INTRODUÇÃO}

LISBOA (1991) ao fazer o histórico da Briologia na Amazônia Brasileira, observou que o estudo das briófitas na Amazônia está muito abaixo, quantitativamente, do de outros grupos vegetais. A percentagem da brioflora conhecida, nessa região, em relação ao número de espécies já referidas no mundo, está em torno de $2,46 \%$, evidenciando a necessidade urgente de aumentar o número de coletas e identificações desse grupo na Amazônia (LISBOA, 1993a). Recentemente, LISBOA (1994), relacionou e ilustrou 14 espécies de musgos e duas de hepáticas como novas ocorrências para o estado do Pará. Este trabalho é uma continuação do anterior, com a finalidade de apresentar algumas espécies de musgos (Bryophyta), coletadas na zona urbana de Belém e alguns municípios do Estado do Pará e confirmadas como novas ocorrências, ampliando a distribuição geográfica do grupo dentro do Brasil e o conhecimento da brioflora naquele estado.

\section{MATERIAL E MÉTODOS}

Procedeu-se à identificação de material coletado na zona urbana do municipio de Belém, na Estação Científica Ferreira Penna (Caxiuanã, município de Melgaço), Serra Pelada (município de Parauapebas) e Rio Iriri (município de Altamira), no periodo de 93 a 96 . As identificações foram feitas utilizando-se chaves e descrição de autores relacionados em LISBOA (1994) e os trabalhos em SHARP et al. (1994).

Para comprovar as espécies que ainda não tinham sido citadas para o estado do Pará, foram utilizados os "checklists" de YANO $(1981 ; 1984 ; 1989 ; 1995)$.

Para cada espécie relacionada,

1 Museu Paraense Emilio Goeldi, Departamento de Botânica, Caixa Postal 399, CEP 66.040-170 Belém, Pará, Brasil. 
são fornecidos dados sobre a coleta, fotomicrografias e alguns comentários morfológicos, taxonômicos e ecológicos.

As fotomicrografias foram feitas em um fotomicroscópio Nikon.

As lâminas para as fotomicrografias foram preparadas com uma mistura de glicerina $(30 \%)$ e água $(70 \%)$.

O material estudado está sendo incorporado ao Herbário do Museu Paraense Emílio Goeldi ( MG ).

\section{RESULTADOS}

Foram identificadas 11 espécies de musgos que ainda não haviam sido referidas para o Estado do Pará. São apresentadas a seguir, em ordem alfabética de familia.

\section{BARTRAMIACEAE}

Philonotis hastata (Duby) Wijk \& Marg. Taxon 8:74.1959 (Fig.1)

Basiônimo : Hypnum hastatum Duby in Moritzi, Syst, Verz. Zoll. Pfl. Java. 132. 1846.

Tipo: Java, col. Duby, 1813.

Material examinado: Brasil, estado do Pará, município de Belém, Parque Zoobotânico do Museu Paraense Emílio Goeldi, sobre pedras nos caminhos em bosque misto, col. R. Lisboa, A. L. IlkiuBorges \& M. Rosa 1279, 27.IV.1992, det. A. L. Ilkiu-Borges.

Comentários: plantas até $20 \mathrm{~mm}$ de altura, em tufos pequenos, densos, filídios lanceolados, costa forte terminando poucas células abaixo do ápice, células do ápice do filidio alongadas, retangulares na parte mediana, quase quadradas na região alar, células superiores unipapilosas pela projeção da parede celular, células inferiores levemente papilosas a lisas. Margens duplamente serreadas acima, serreadas, serruladas ou inteiras para a base. Descrição mais detalhada em LISBOA (1993b). Espécie coletada em local úmido e sombreado, Já referida para o estado de Rondônia (LISBOA \& YANO, 1987). Segundo GRIFFIN III (1994) é uma espécie pantropical.

Philonotis uncinata (Schwaegr.) Brid., Bryol. Univ. 2:22.1827. (Fig. 2).

Basiônimo: Bartramia uncinata Schwaegr., Spec. Musc. Suppl. 1(2):60.1816.

Tipo: Guadalupe e Martinica, col. Richard s.n.

Material examinado: Brasil, estado do Pará, municipio de Belém: Parque Zoobotânico do Museu Paraense Emílio Goeldi, sobre pedras no caminho em bosque misto, col. R. Lisboa, A.L. IlkiuBorges \& M. Rosa 1254, 27.IV.1992, det. A.L. Ilkiu-Borges; Campus de Pesquisa do Museu Paraense Emílio Goeldi, sobre pedras da vala do jardim do DBO, col. R. Lisboa \& A.L. IlkiuBorges 1160, 26.III.1992, det. A.L. IlkiuBorges; Praça Batista Campos, sobre pedra, col. A.L. Ilkiu-Borges 150, 24.IV.1993, det. A.L. Ilkiu-Borges; Bosque Rodrigues Alves, sobre pedra, col. A.L. Ilkiu-Borges, M.C. Cavalcante \& M.C. Silva 49, 26.III.1993, det. A.L. Ilkiu-Borges; idem, col. A.L. Ilkiu Borges, M.C. Cavalcante \& M.C. Silva 52, 26.III.1993, det. A.L. Borges; idem, col. A.L. Ilkiu-Borges, M.C. Cavalcante \& M.C. Silva 72, 26.III.1993, det. A.L. Ilkiu-Borges; idem, A. L. Ilkiu-Borges, M.C. Cavalcante \& M.C. Silva 77, 26.III.1993, det. R. Lisboa \& A.L. Ilkiu-Borges; Faculdade de Ciências 


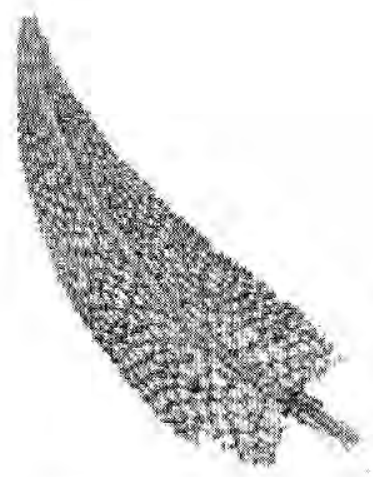

A

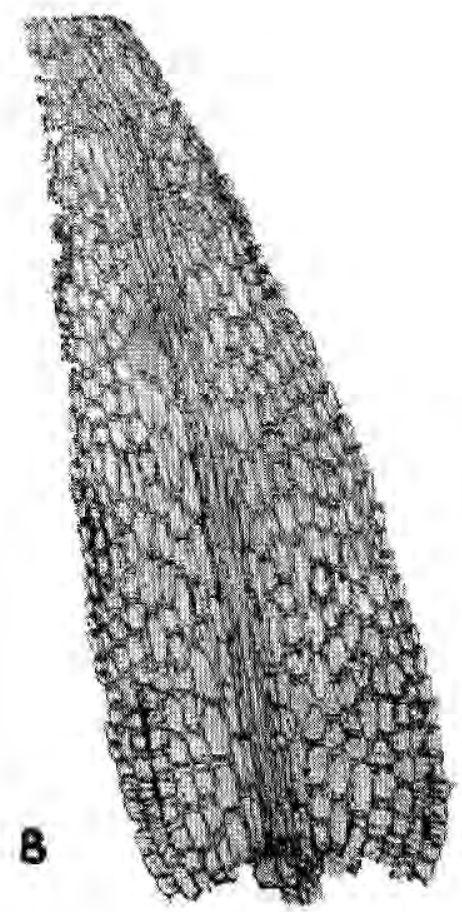

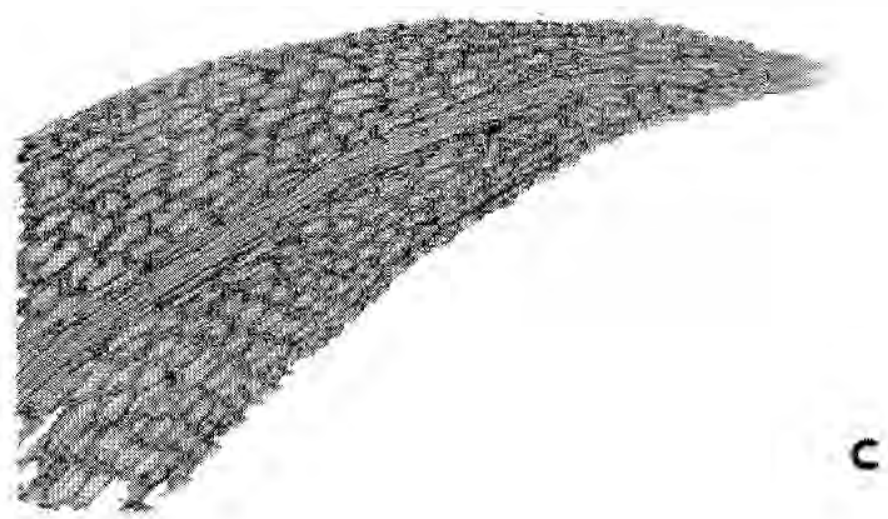

Figura 1. Philonotis hastata. A) Filidio inteiro, 73X; B) Detalhe das regiões mediana e basal, 183X; C) Detalhe do ápice curto-excurrente e margens duplamente serreadas, $183 X$ (R.Lisboa, 1279). 

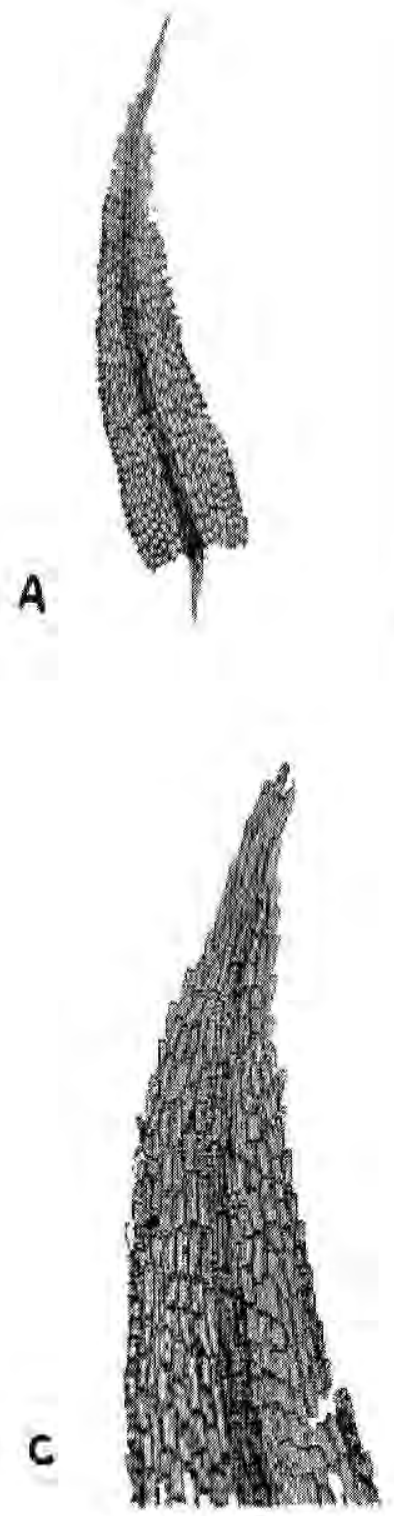
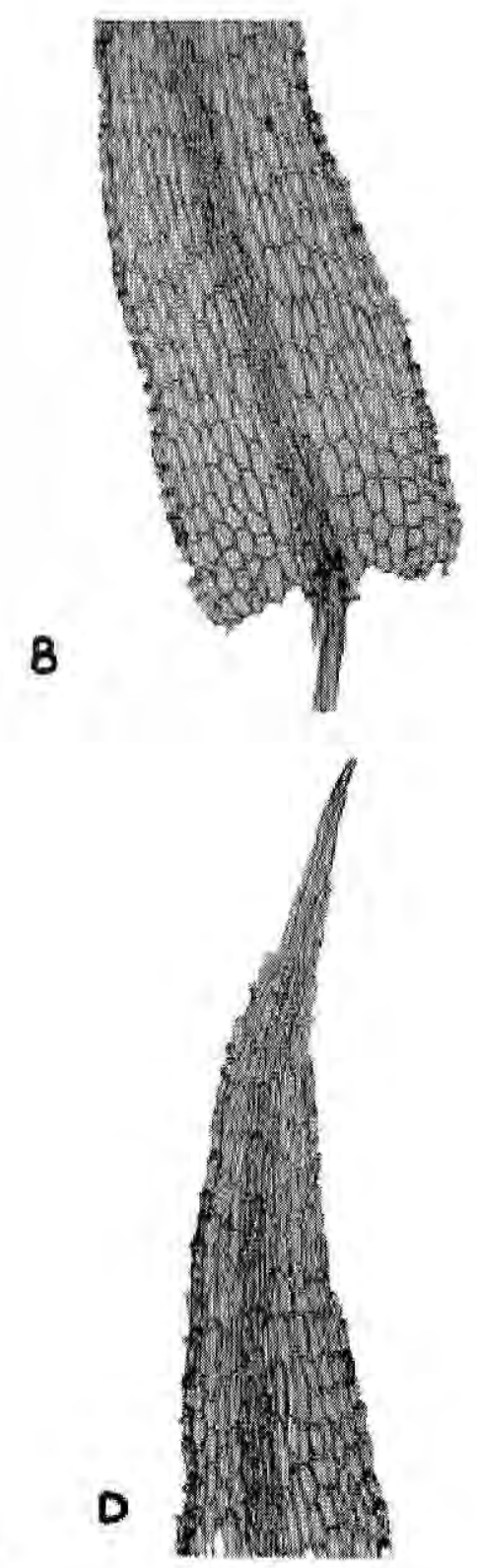

Figura 2. Philonotis uncinata, A) Filídio inteiro, $73 \mathrm{X}$; B) Detalhe da região basal, destacandose as papilas nos ápices superiores, $183 \mathrm{X}$; C e D) Dois ápices diferentes de filidios pertencentes à mesma planta, 183X (R. Lisboa, 1254). 
Agrárias do Pará, sobre vala, col. A.L. Ilkiu-Borges \& M.C. Silva 550, 18.V.1994, det. A. L. Ilkiu-Borges; Bairro do Marco, Tv. Mauriti, sobre calçada, col. A.L. Ilkiu-Borges \& F. Borges 371, 22.II.1994, det. A.L. IlkiuBorges; idem, Pass. Cristina, sobre muro, col. A.L. Ilkiu-Borges \& F Borges 376, 22.II.1994, det. A.L. IlkiuBorges; idem, Rua Angustura, sobre muro, col. A.L. Ilkiu-Borges \& M.C. Silva 403, 03.III.1994, det. A.L. IlkiuBorges; idem , Av. $1^{\circ}$ de Dezembro, sobre calçada, col. A.L. Ilkiu-Borges \& M.C. Silva 426, 04.III.1994, det. A.L. Ilkiu-Borges; idem, col. A.L. IlkiuBorges \& M.C. Silva 429, 04.III.1994, det. A.L. Ilkiu-Borges; Bairro Pedreira, Rua Estrela, sobre parede de casa, col. A.L. Ilkiu-Borges \& M.C. Silva 450, 07.IV.1994, det. A.L. Ilkiu-Borges; idem, Av. Humaitá, sobre muro, col. A .L. Ilkiu-Borges \& M.C. Silva 458, 07.IV.1994, det. A.L. Ilkiu-Borges; idem, Av. Pedro Miranda, sobre calçada, col. A.L. Ilkiu-Borges \& M.C. Silva 471, 07.IV.1994, det. R. Lisboa; Bairro Matinha, Pass. Só Vendo, sobre vala, col. A .L. Ilkiu-Borges \& M.C. Silva 497, 14.IV.1994, det. A.L. IlkiuBorges; idem sobre pedra, col. A .L. Ilkiu-Borges \& M.C. Silva 499, 14.IV.1994, det. A.L. Ilkiu-Borges; idem, sobre parede de casa, col. A.L. Ilkiu-Borges \& M.C. Silva 501, 14.IV.1994, det. A.L. Ilkiu-Borges; idem, Pass. Lameira, sobre muro, col. A.L. Ilkiu-Borges \& M.C. Silva 502, 14.IV.1994, det. A .L. Ilkiu-Borges; idem, sobre vala, col. A.L. IlkiuBorges \& M.C. Silva 504, 14.IV.1994, det. A.L. Ilkiu-Borges; idem, Rua
Antônio Barreto, sobre muro, col. A .L. Ilkiu-Borges \& M.C. Silva 506, 14.IV.1994, det. AL. Ilkiu-Borges; idem, col. A.L. Ilkiu-Borges \& M.C. Silva 507, 14.IV.1994, det. A.L. IlkiuBorges; Bairro Reduto, Av. Diogo Móia, sobre vala, col. A.L. IlkiuBorges \& M.C. Silva 517, 14.IV.1994, det. A.L. Ilkiu-Borges; Bairro Sousa, Pass. Elieser Levy, sobre calçada, col. A .L. Ilkiu-Borges \& M.C. Silva 540, 17.V.1994, det. A.L. Ilkiu-Borges; idem, sobre muro, col. A .L. IlkiuBorges \& M.C. Silva 545, 17.V.1994, det. A.L. Ilkiu-Borges; idem, col. A.L. Ilkiu-Borges \& M.C. Silva 546, 17.V.1994, det. A.L. Ilkiu-Borges; Bairro Guamá, Rua Igarapé-Mirim, sobre calçada, col. A.L. Ilkiu-Borges \& M.C. Silva 574, 18.V.1994, det. A.L. IlkiuBorges; Bairro Acampamento, Rua Barão do triunfo, em quintal próximo a vala, col. A.L. Ilkiu-Borges \& M.C. Silva 585, 25.V.1994, det. A.L. Ilkiu-Borges; idem, sobre vala, col. A.L. IlkiuBorges \& M.C. Silva 587, 25.V.1994, det. A.L. Ilkiu-Borges.

Comentários: plantas até $15 \mathrm{~mm}$ de altura (GRIFFIN III (1994) encontrou até $30 \mathrm{~mm}$ de altura), em tufos; filídios eretos, um pouco curvados quando secos, lanceolados, ápice agudo-obtuso, costa forte, curto-excurrente, células alongadas a retangulares, papilas nos ápices superiores; margens serradas com papilas se projetando para fora da margem. Segundo GRIFFIN III (1994), está espécie é um complexo de expressões variadas, como atestado por uma grande sinonímia, já discutido em FLORSCHÜTZ (1964) e LISBOA (1993a). GRIFFIN III (1994) acha conveniente reconhecer a var. 
uncinata (com caulídios curvados e costa excurrente), var. glaucescens (Hornsch.) Florsch. (com caulídios retos e costa percurrente e var. gracillima (Ångstr.) Florsch. (com ápice dos filídios obtusos e costa subpercurrente). Esta classificação seria ótima se não ocorresse dentro da mesma população e até nas mesmas plantas, filídios que se enquadram em todas as três categorias, o que foi observado por GRIFFIN III (1994) e é mostrado, em parte, nas Figuras $2 \mathrm{C}$ e $2 \mathrm{D}$.

Espécie coletada em locais que conservam umidade ou que estejam constantemente úmidos, como em valas. $\mathrm{Na}$ cidade de Belém, esta espécie apresentou grande adaptabilidade à zona urbana, em locais com poluição.

Ocorre desde o México até o Brasil, sudeste dos Estados Unidos, Ilhas Ocidentais, África, Austrália e Oceania. No Brasil, foi coletada em Mato Grosso, Amazonas, Minas Gerais, Rio de Janeiro, Santa Catarina e Rondônia, YANO (1995) acrescenta Espírito Santo, Pernambuco e Paraíba e COSTA (1995) para o estado do Acre.

\section{BRYACEAE}

Bryum apiculatum Schwaegr., Spec. Musc, Suppl. 1(2):102, 1816. (Fig. 3)

Tipo: América meridional, col. Richardus.

Material examinado: Brasil, estado do Pará, município de Belém, Bairro do Guamá, Rua Barão de Igarapé-Mirim, sobre calçada, col, A.L. Ilkiu-Borges \& M.C. Silva 577, 18.V.1994, det. A.L. IlkiuBorges; idem, sobre parede de casa, col. A.L. Ilkiu-Borges \& M.C. Silva 575, 18.V.1994,det. A.L. Ilkiu-Borges;
Campus de Pesquisa do Museu Paraense Emílio Goeldi, sobre vala no DBO, col. R. Lisboa \& A.L. IlkiuBorges 1166, 26.III.1992, det. A.L. Ilkiu-Borges.

Comentários: plantas em tufos, caulídios avermelhados. Filídios côncavos, oblongos a oblongo-lanceolados, curto ou longo apiculados, apresentando gemas axilares avermelhadas ou marromavermelhadas, largamente oblongas ou bulbosas; margens planas, não bordeadas, inteiras, células oblongoromboidais, abruptamente mais largas abaixo. O caulídio vermelho, contrastando com filídios verde-amarelados e a presença de gemas axilares avermelhadas são características importantes na identificação da espécie.

Segundo OCHI et al. (1994), é uma espécie pantropical, ocorrendo dentro de áreas temperadas nos hemisférios Norte e Sul.

No Brasil, relacionada para o estado do Amazonas como Bryum cruegeri Hampe ex. C. Muell. e como B. apiculatum para o Rio Grande do Sul, Santa Catarina e São Paulo (YANO, 1981). É referida para a Paraíba, por YANO (1995).

Bryum capillare Hedw., Spec. Musc. 182. 1801. (Fig. 4)

Tipo: ligna putrida Europae.

Material examinado: Brasil, estado do Pará, município de Belém, Bairro da Matinha, Rua 3 de maio, sobre tronco de árvore, col. A.L. IlkiuBorges \& M.C. Silva 524, 14.IV.1994, det. A.L. Ilkiu-Borges.

Comentários: gametófitos muito característicos quando secos pelos filídios fortemente enrolados espiralmente 

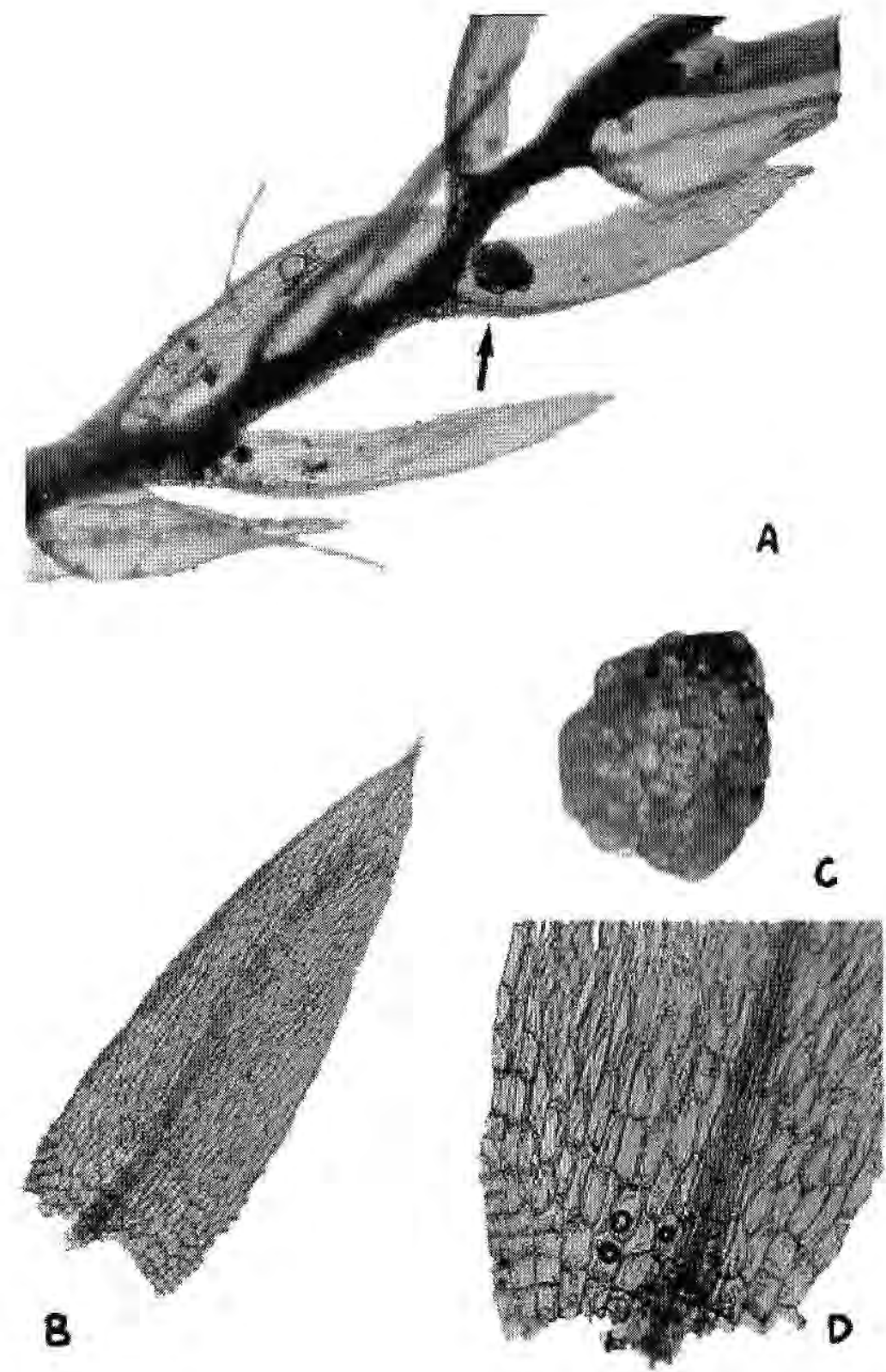

Figura 3. Bryum apiculatum. A) Detalhe do caulidio, evidenciando uma gema axilar, $73 \mathrm{X}$; B) Filídio inteiro, 73X; C) Gema axilar, 183X; D) Detalhe da base do filidio, 183X (A. L. Ilkiu-Borges, 575). 

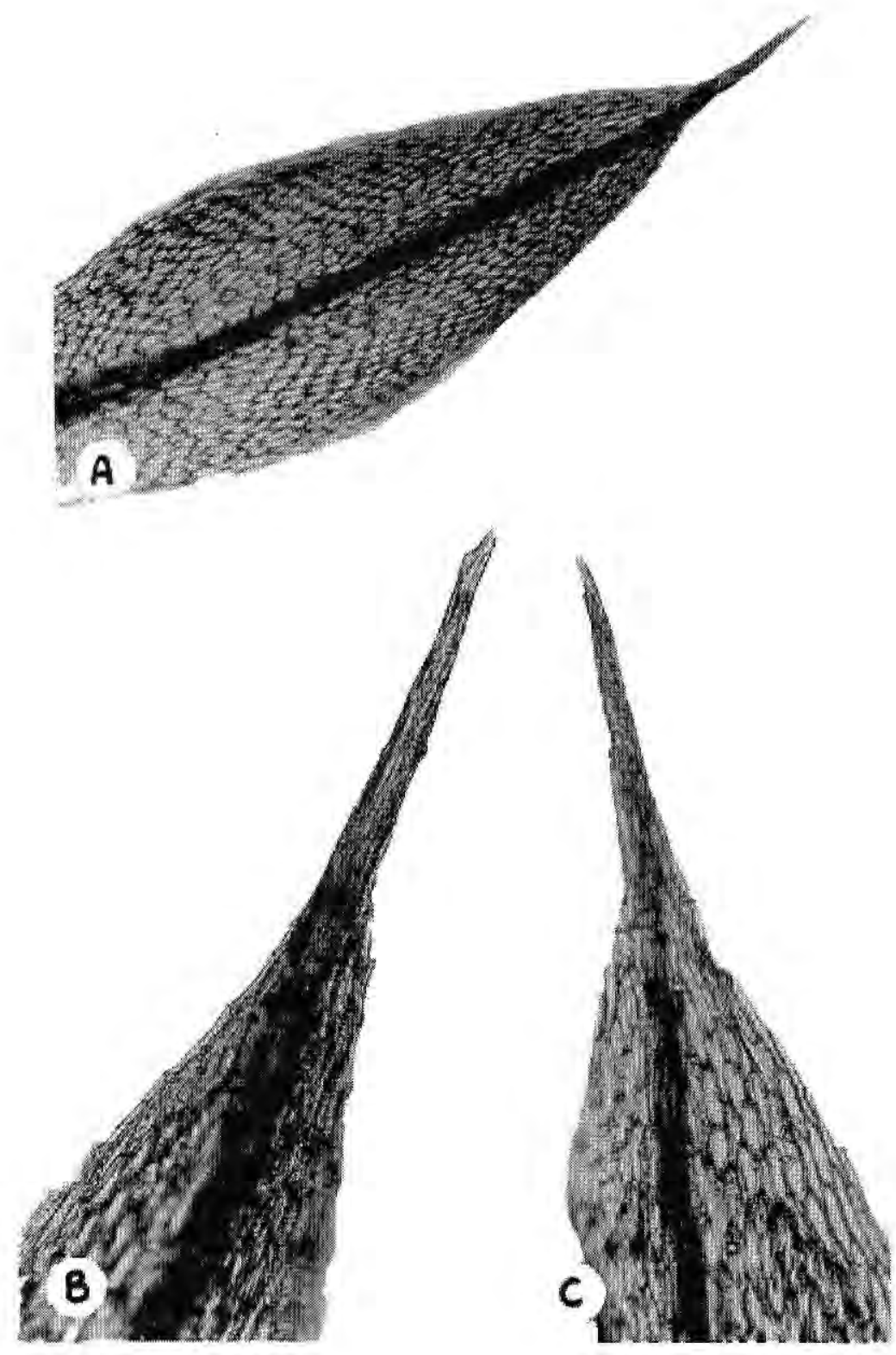

Figura 4. Bryum capillare. A) Filidio, 73X; B e C) Detalhes dos ápices, 183X (A. L. Ilkiu-Borges, 524). 
ao redor do caulídio, com longos ápices flexuosos. Filídios oblongo-espatulados, estreitando para a base; costa forte, excurrente em um ápice pilifero, muito longo; margem finamente denteada acima ou inteira, borda distinta, formada por 3 a 5 fileiras de células longas e estreitas. Células basais largamente retangulares, as superiores rombóide-hexagonais.

Segundo SYED (1973), possui distribuição quase cosmopolita e cresce numa grande variedade de habitats: troncos e ramos de árvores, rochas, muros e até sobre o solo. OCHI et al. (1994) a consideram cosmopolita.

No Brasil é referida para o Rio de Janeiro (SYED, 1973), Ceará, Pernambuco, Mato Grosso, Goiás, Minas Gerais, São Paulo, Santa Catarina (YANO, 1989), Rondônia (LISBOA, 1993b) e Espírito Santo (YANO, 1995).

\section{DICRANACEAE}

Campylopus pilifer Brid., Musc. Recent. Suppl. 4:72. 1819. (Figura 5)

Tipo: Itália, Ischia, col. Bridel s.n.

Material examinado: Brasil, estado do Pará, município de Parauapebas, Serra dos Carajás, Canga N1, sobre rocha de minério de ferro em vegetação de canga, col. R. Lisboa, C. Rosário \& J.S. Ramos 1467, 14.X.1992, det. R. Lisboa; idem, col. R. Lisboa, C. Rosário \& J.S. Ramos 1472, 14.X.1992, det. F. Ilkiu-Borges; idem, Canga N3, sobre cupinzeiro, col. J. Sales \& C. Rosário 128, 23.III.1993, det. F. Ilkiu-Borges; idem, Canga N1, $1^{\circ}$ ramal à direita, sobre pedra e terra, col. J. Sales \& C. Rosário 240, 24.III.1993, det. F. Ilkiu-Borges.

Comentários: plantas em tufos rígidos, verdes a marrom-esverdeadas, vermelho-tomentosas; filidios ovaladolanceolados, margens inteiras, ápice hialino, serreado, variando em comprimento, mas geralmente longo, células alares pouco diferenciadas, hialinas a avermelhadas, células basais longo-retangulares, as superiores ovaladas a oblongo-rômbicas. Em corte transversal, lamelas dorsais com 3 a 4 células de altura. $O$ epíteto específico refere-se à principal característica morfológica, o ápice pilifero dos filídios. A cor hialina é claramente distinta.

Ocorre sobre pedras expostas, solos secos e margens de rodovias. Segundo FRAHM (1991), apresenta uma larga amplitude ecológica, ocorrendo de semidesertos a florestas úmidas e do nivel do mar até $4.800 \mathrm{~m}$ de altitude. Possui padrão de distribuição Neotropical, chegando até o norte da Argentina. Também ocorre na América do Norte, Europa, África, Índia e Sri Lanka (FRAHM, 1991).

No Brasil, relacionada para Minas Gerais, Rio de Janeiro, Paraná e Roraima (YANO, 1989), Alagoas, Bahia, Rio Grande do Sul, São Paulo (FRAHM, 1991) e Espirito Santo (YANO, 1995).

\section{FISSIDENTACEAE}

Fissidens allenianus Brugg.Nann. \& Pursell, Bryologist, 93:332. 1990. (Fig. 6)

Tipo: U.S.A. Flórida, DADECO, col. Pursell 2915,

Material examinado: Brasil, estado do Pará, município de Belém, Bosque Rodrigues Alves, sobre pedra, col. A.L. Ilkiu-Borges, M.C. Cavalcante \& M.C. Silva 77, 26.III.1993, det. R. Lisboa \& A .L. Ilkiu-Borges. 

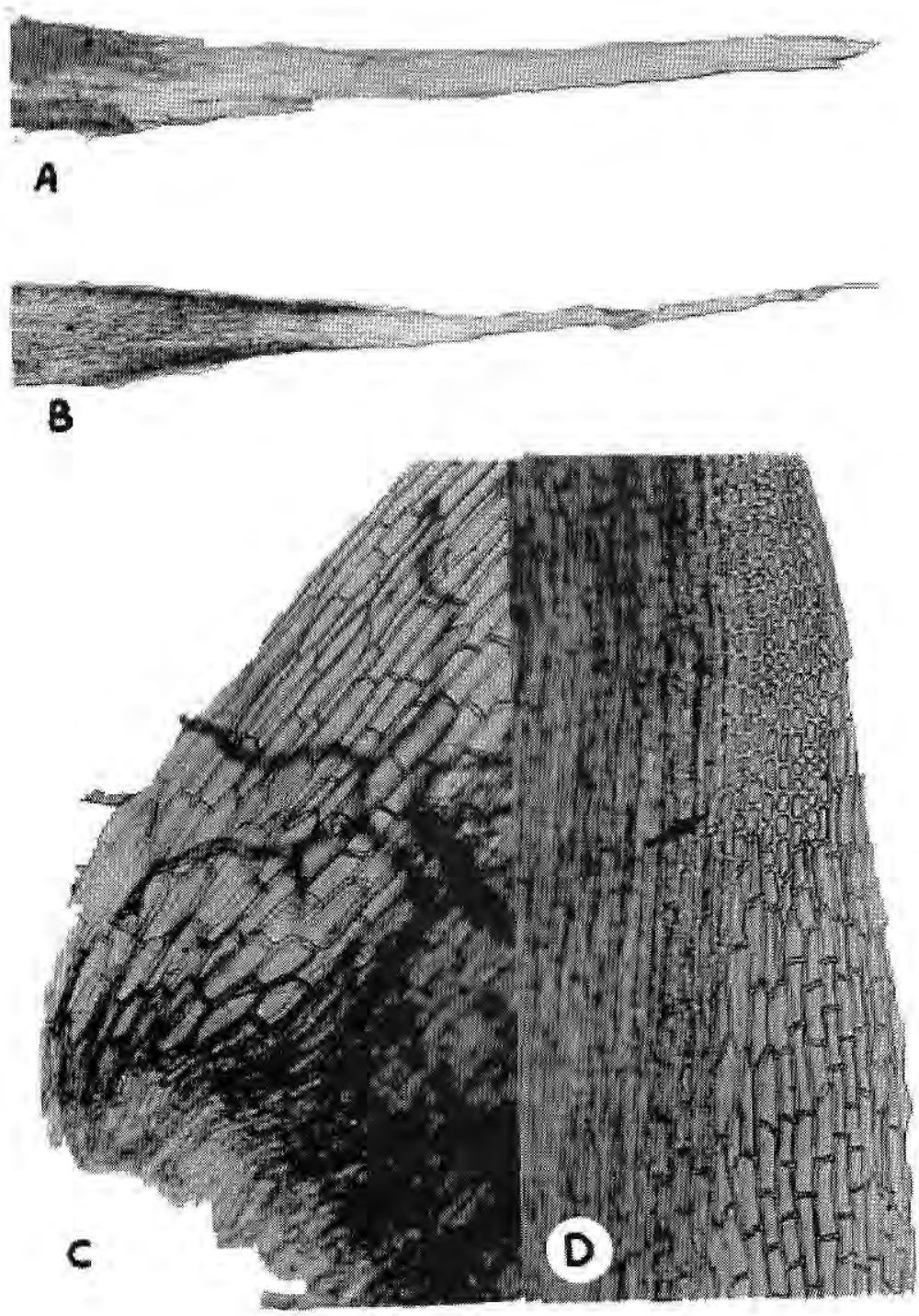

Figura 5. Campylopus pilifer. A) Ápice pilifero e hialino do filidio, 183X; B) Outro ápice, $73 \mathrm{X}$; C) Células basais e alares do filídio, 183X; D) Células do filidio, evidenciando a separação das células superiores das inferiores, 183X (R. Lisboa, 1467). 

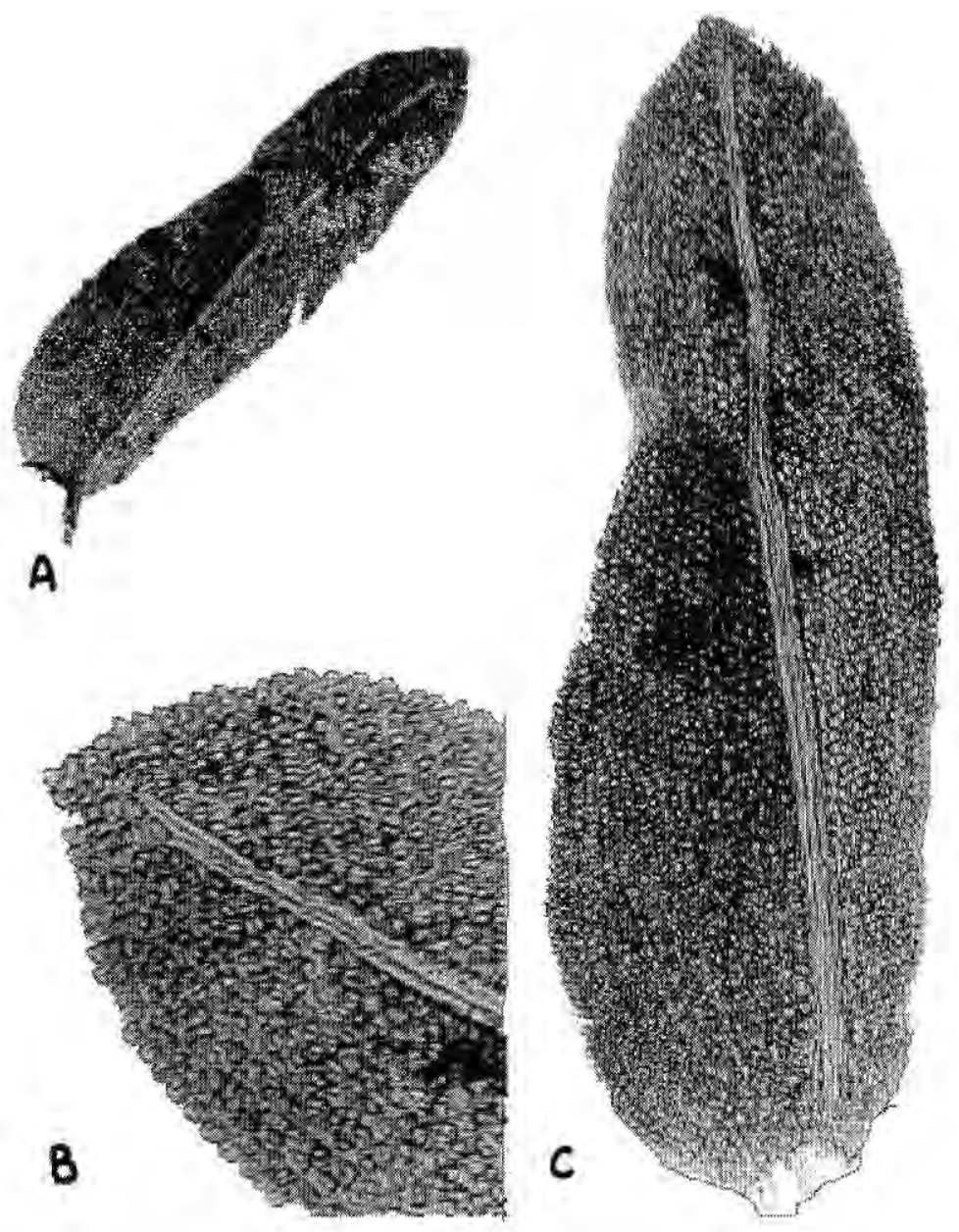

Figura 6. Fissidens allenianus. A) Filidio inteiro, 73X; B) Detalhe do ápice, evidenciando células saliente-espessadas, 366X; C) Filídio inteiro, 183X (A. L. Ilkiu-Borges, 77). 
Comentários: gametófitos eretos a decumbentes, não a moderadamente ramificados, crescendo espalhados. Filídios oblongos, ligulados, persistentes, margens crenuladas estreitando abruptamente para um ápice redondo-obtuso, caracteristica esta difícil de reconhecer, segundo BRUGGEMAN-NANNENGA \& PURSELL (1990), devido os filídios apresentarem-se dobráveis. Costa proeminente, terminando 5 a 7 e até 10 células abaixo do ápice do filídio. Células da lâmina lisas, saliente-espessadas.

Espécie muito afim com $F$ radicans Mont., da qual BRUGGMANNANNENGA \& PURSELL (1990) consideraram distinta, fundamentando-se na caducidade dos filídios em $F$ radicans e persistentes em $F$. allenianus, junto ao perístoma, reduzido em $F$ radicans e completo em $F$ a allenianus. Nos exemplares estudados neste trabalho, não foi encontrado perístoma, estando a classificação baseada nos caracteres vegetativos com filídios persistentes, o que mais caracterizou $F$ allenianus.

Segundo BRUGGMAN-NANNENGA \& PURSELL (1990), Pursell et al. (1992) e Pursell (1994), F, allenianus se distribui do sudeste da Flórida, ilhas Bahamas, ocidente do México e América Central, não ocorrendo na América do Sul, onde está registrado apenas $E$ radicans. Mas baseado no caráter caducidade dos filídios, não encontrado no exemplar examinado, acredita-se que, pelo menos para o estado do Pará, F. allenianus é a espécie que ocorre.

Coletado sobre pedra em local sombreado, muito próximo ao solo.

Fissidens pellucidus Hornsch., Linnaea 15:146.1841. 1979 (Fig.7).
Tipo: Suriname

Material examinado: Brasil, estado do Pará, município de Belém, Reserva Mocambo, mata de terra firme, sobre cupinzeiro, col. R. Lisboa, M.R. Santos \& J. Ramos 773, 26.XI.1985, det. R. Lisboa.

Comentários: plantas maioria marrom-avermelhadas, com filídios oblongos-lanceolados, ápice agudo a obtuso, células da lâmina lisas, pelúcidas, gutuladas (com uma fina mancha, parecendo gota, aparentemente uma inclusão oleosa refrativa), irregularmente hexagonais, margens crenuladas, formadas por uma fileira de células menores, mais ou menos pentagonais a quadrado-arredondadas. Lâmina vaginante abaixo da metade inferior do filídio e mais estreita que a lâmina do filidio.

Espécie referida para os estados de Mato Grosso, Goiás, Minas Gerais, Paraná, Rio de Janeiro e Santa Catarina, segundo YANO (1981).

\section{HOOKERIACEAE}

Calliscostella merkelii (Hornsch.) Jaeg., Ber. S. Gall. Naturw. Ges. 187576:351, 1877 (Ad. 2:255) (Fig. 8).

Basiônimo: Hookeria merkelii Hornsch., Fl. Bras. 1(2):62. 1840.

Tipo: Brasil, Sebastianopolin, col. Merkel s.n.

Material examinado: Brasil, estado do Pará, município de Belém, Parque Zoobotânico do Museu Paraense Emílio Goeldi, sobre pedras em bosque misto, com plantas naturais e introduzidas, col. R. Lisboa, A.L. Ilkiu-Borges \& M. Rosa 1263, 27.IV.1992, det. A.L. Ilkiu-Borges.

Comentários: Plantas verde-pálidas a 
A
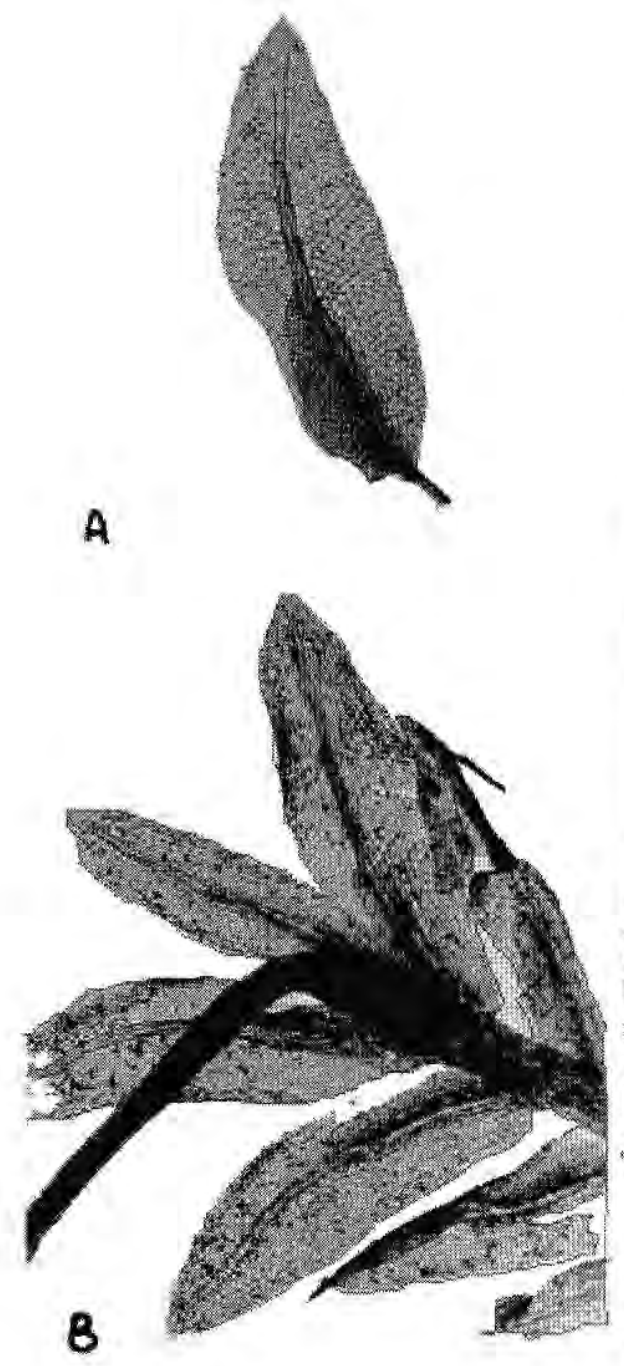

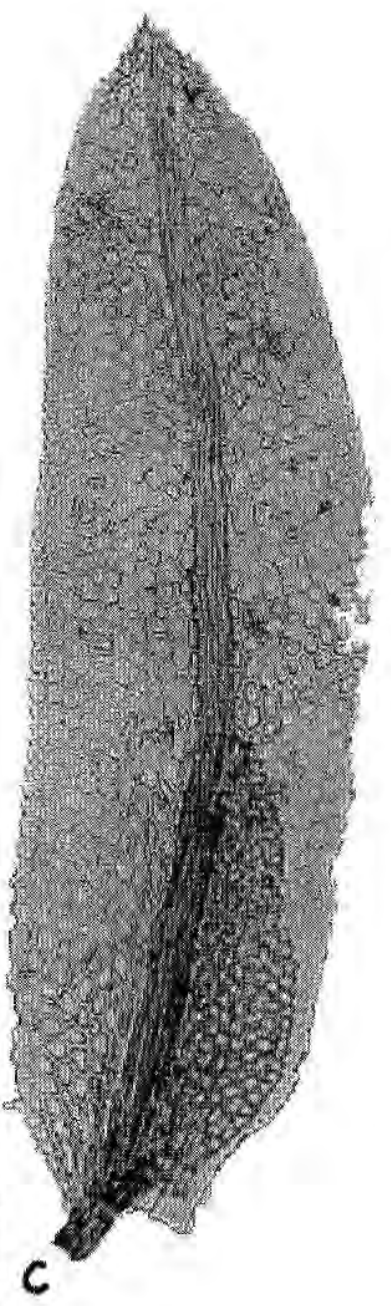

Figura 7. Fissidens pellucidus. A) Filidio inteiro, 73X; B) Ápice do caulidio, com disposição dos filídios e seta, 73X; C) Outro filidio, mais estreito, 183X (R. Lisboa, 773). 

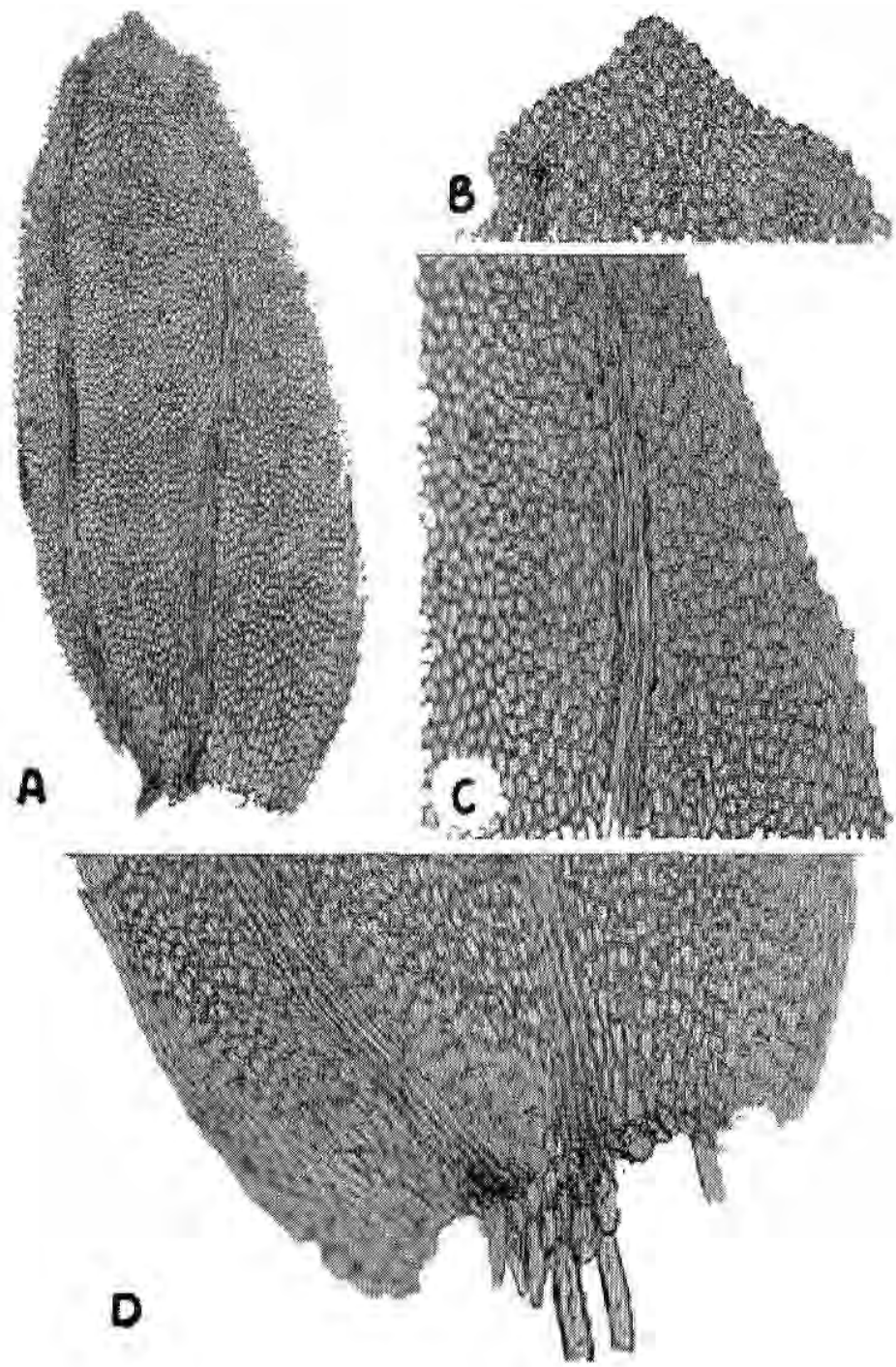

Figura 8. Callicostella merkelii. A) Filidio inteiro, 73X; B) Ápice do filidio, 183X; C) Detalhe da margem serreada, 183X; D) Detalhe da base, I83X (R. Lisboa, 1263). 
marrom-esverdeadas, filídios complanados, oblongo-ligulados, ápice truncado, obtuso a agudo-arredondado, margens superiores serruladas, inteiras para a base, costa dupla firme, quase alcançando o ápice e divergindo a partir da base.

Espécie muito semelhante a Calliscostella pallida (Hornsch.) Ångstr., diferindo desta pelas células da região mediana do filídio, lisas em C. merkelii. Segundo FLORSCHÜTZDE WAARD (1986), C. pallida apresenta células unipapilosas obscuras, enquanto C. merkelii possui as células pelúcidas, lisas ou com uma papila muito pequena sobre o lúmem das células apicais. Quanto aos demais caracteres morfológicos, o exemplar examinado apresenta muita semelhança a C. pallida, dando a impressão de ser uma forma intermediária entre as espécies.

Ocorre no Brasil, Guatemala, Suriname e Guiana Francesa, de acordo com FLORSCHÜTZ -DE WAARD (1986). No Brasil, referido para Minas Gerais, Rio de Janeiro, Santa Catarina e São Paulo (YANO, 1981).

\section{SEMATOPHYLLACEAE}

Taxithelium pluripunctatum (Ren. \& Card.) Buck, Moscosoa 2:60. 1983. (Fig. 9)

Basiônimo:

Trichosteleum pluripunctatum Ren. \& Card., Bull. Soc. Roy. Bot. Belg.

29(1):184. 1890.

Tipo: Martinica.

Material examinado: Brasil, estado do Pará, município de Belém, Reserva do Utinga, sobre árvore morta, col. A .L. Ilkiu-Borges, M.C. Cavalcante \& F. Ilkiu-Borges 263, 26.XI.1993, det. A.L.
Ilkiu-Borges; idem, sobre tronco, col. A .L. Ilkiu-Borges, M.C. Cavalcante \& F. Ilkiu-Borges 278, 26.XI.1993, det. A.L. Ilkiu-Borges; município de Melgaço, Caxiuanã, Estação Científica Ferreira Penna, sobre árvore viva, col. R. Lisboa, C.S. Rosário \& R.P. Bahia 3691, 16.V.1995, det. J. Melo.

Comentários: plantas rasteiras, em tapetes laxos, amarelados; filídios dos caulídios maiores, mais longo-acuminados e menos papilosos que os filídios dos ramos, estes lanceolado-ovalados a acuminados, levemente côncavos, margens planas, inteiras a serruladas, células lineares com 2 a 5 papilas enfileiradas ao longo do lúmem, células alares pouco ou não diferenciadas. A distribuição laxa dos filídios sobre os ramos e as células lisas do ápice são caracteres distintos da espécie.

Segundo BUCK (1985), ocorre na Martinica, Dominica, Guina Francesa e Brasil, maioria sobre troncos de árvores. No Brasil, citada para o Amazonas, Bahia, Roraima (BUCK, 1985) e Pernambuco (PÔRTO, 1990).

Taxithelium portoricense Williams, Bryologist 30:37. 1927. (Fig. 10)

Tipo: Porto Rico perto Cidra, col. E G. Britton 8390, III-1925.

Material examinado: Brasil, estado do Pará, município de Belém, Reserva do Utinga, sobre árvore viva, col. A .L. Ilkiu-Borges, M.C. Cavalcante \& F. Ilkiu-Borges 251, 26.XI.1993, det. A .L. Ilkiu-Borges; idem, sobre pedra na beira do lago, col. A .L. Ilkiu-Borges, M.C. Cavalcante \& F. Ilkiu-Borges 283, 26.XI.1993, det. A .L. Ilkiu-Borges; município de Parauapebas, Serra dos Carajás, Acampamento do DOCEGEO no Km 41 da estrada N1-Projeto Bahia, 


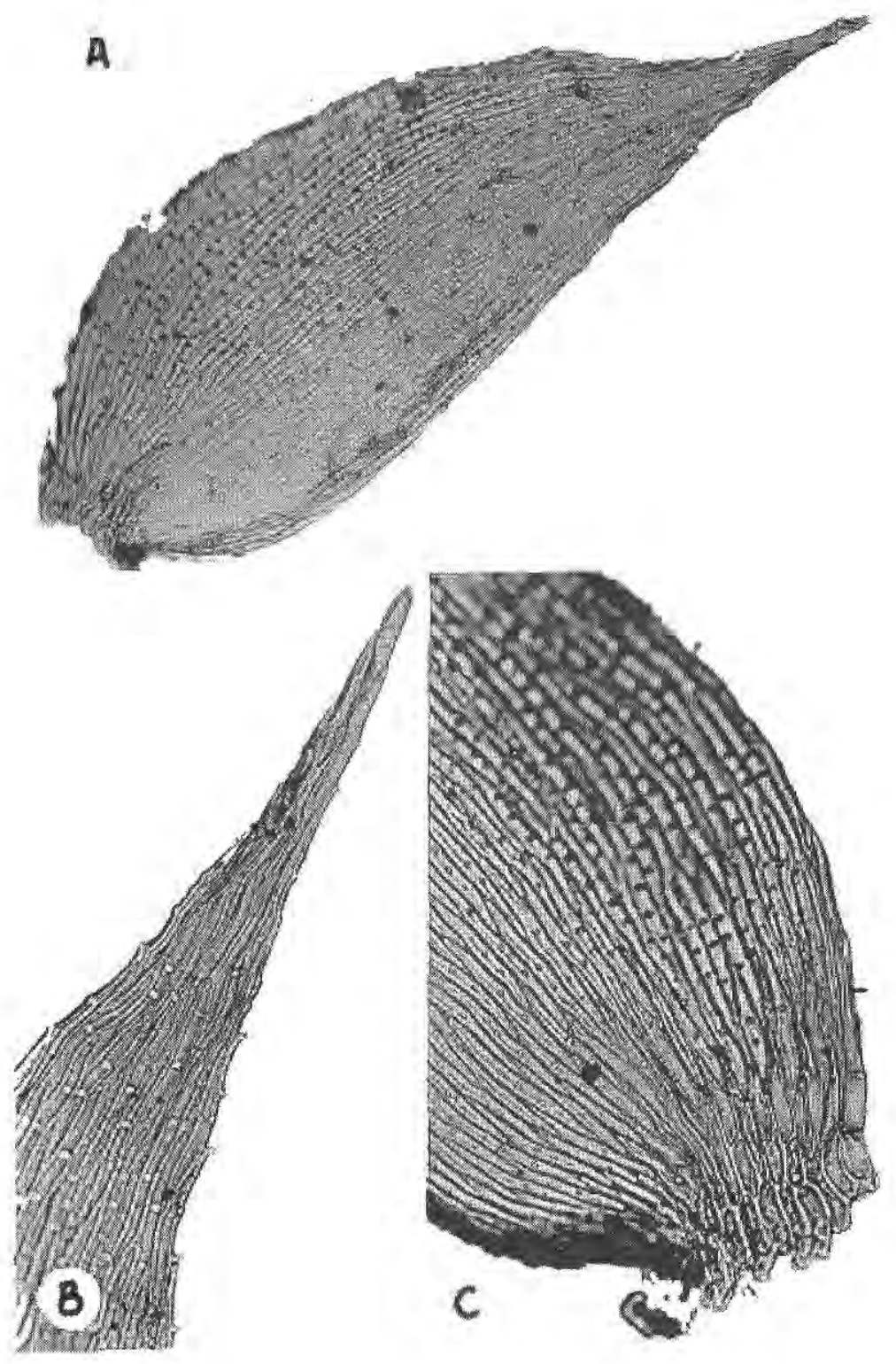

Figura 9. Taxithelium pluripunctatum. A) Filidio inteiro, 183X; B) Detalhe do ápice, 366X; C) Detalhe da base, $366 \mathrm{X}$ (A. L. Ilkiu-Borges, 278). 


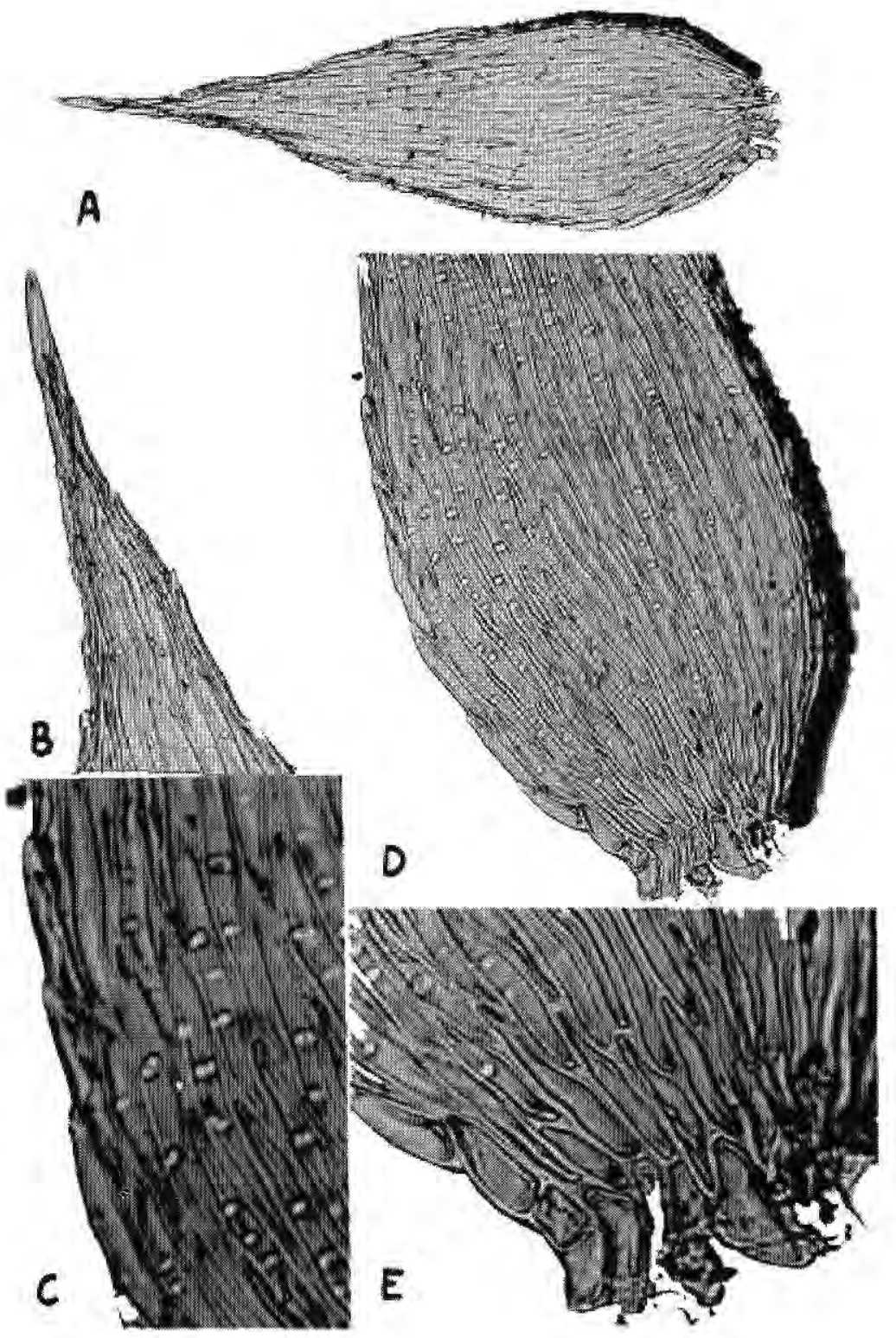

Figura 10. Taxithelium portoricense. A) Filidio inteiro, 183X; B) Ápice do filidio, 366X; C) Detalhe da margem do filídio, 732X; D) Região mediana e basal do filidio, 366X; E) Detalhe da base do filidio, $732 \times$ (A. L. Ilkiu-Borges, 251). 
sobre solo argiloso na margem do igarapé Cotia, col. R. Lisboa, C.S. Rosário \& J.S, Ramos, 18.X.1992, det. F. Ilkiu-Borges.

Comentários: gametófitos delicados, verde-pálidos, filídios dos ramos ligeiramente côncavos, com uma das margens quase sempre involuta, oblongolanceolados, ápice estreitamente agudo, margem serrulada, células lineares, com 3 a 5 pequenas papilas enfileiradas sobre $o$ lúmem, células alares pouco diferenciadas, apenas 2 a 3 pouco infladas, com células subquadradas acima. A forma do filídio oblongo-lanceolada e uma das margens involuta distingue bem esta espécie. Segundo CRUM (1994), ocorre no México, Cuba, Jamaica, Porto Rico, República Dominicana e Martinica. Esta é a primeira referência para o Brasil.

\section{THUIDIACEAE}

Cyrto-hypnum involvens (Hedw.) Buck \& Crum, Contr. Univ. Michigan Herb. 17:66. 1990. (Fig. 11)

Basiônimo: Leskea involvens Hedw., Spec. Musc. 218:1801.

Tipo: Jamaica.

Material examinado: Brasil, estado do Pará, município de Belém, Faculdade de Ciências Agrárias do Pará, sobre raiz de leguminosa, col. A .L. Ilkiu-Borges \& M.C. Silva 560, 18.V.1994, det. A.L. Ilkiu-Borges; idem, Campus de Pesquisa do Museu Paraense Emílio Goeldi, sobre pedras na vala do DBO, col. R. Lisboa \& A .L. Ilkiu-Borges 1168, 26.III.1992, det. A .L. Ilkiu-Borges; idem, sobre murinho da vala do DBO, col. R. Lisboa \& A .L. Ilkiu-Borges 1173, 26.III.1992, det. A .L. Ilkiu-Borges; idem, Bosque Rodrigues Alves, sobre pedra e areia, col. A .L. Ilkiu-Borges \& M. Rosa 15, 17.III.1993, det. A.L. Ilkiu-Borges; idem, sobre pedra, col. A .L. Ilkiu-Borges \& M. Rosa 37, 17.III.1993, det. A .L. Ilkiu-Borges; idem, Área de Pesquisas Ecológicas do Guamá-APEG, sobre tronco podre, col. R. Lisboa, R.P. Bahia \& J. Sales 788, 17.II.1986, det. R. Lisboa; idem, sobre árvore viva, col. R. Lisboa 796, 3.III.1986, det. R.Lisboa; idem, sobre tronco vivo, col. R. Lisboa, M. Rosa \& J. Sales 804, 16.IV.1986, det. R. Lisboa; município de Altamira, RioIriri, Pico da Topografia $\mathrm{n} \cong 203$, sobre pedaço de pau podre, col. S.A . da M. Souza, U.N. Maciel, O.C. Nascimento \& M.C. da Silva 109, 23.VIII.1986, det. O. Yano.

Comentários: gametófitos pequenos, verde-escuros a amarelados, caulídios prostrados, 1 a 2 pinados, filídios eretoincurvados quando secos, expandidos quando úmidos, filídios dos ramos incurvado-catenulados ou enrolados quando secos, expandidos quando úmidos, assimétricos, oblongo-ovalados, obtusos ou rombudos, células superiores redondo-hexagonais, minúscula papilosas, filídios periqueciais inteiros, não franjados. Segundo CRUM \& BUCK (1994), ocorre do México ao norte da América do Sul, Ilhas Ocidentais e Flórida. No Brasil, referida para o Amazonas e Mato Grosso (YANO, 1981), Amazonas (GRIFFIN III, 1979) e Amapá (YANO \& LISBOA, 1988), como Thuidium involvens (Hedw.) Mitt. Mais recentemente citada para Nova Friburgo, Rio de Janeiro, por COSTA (1995), Minas Gerais 

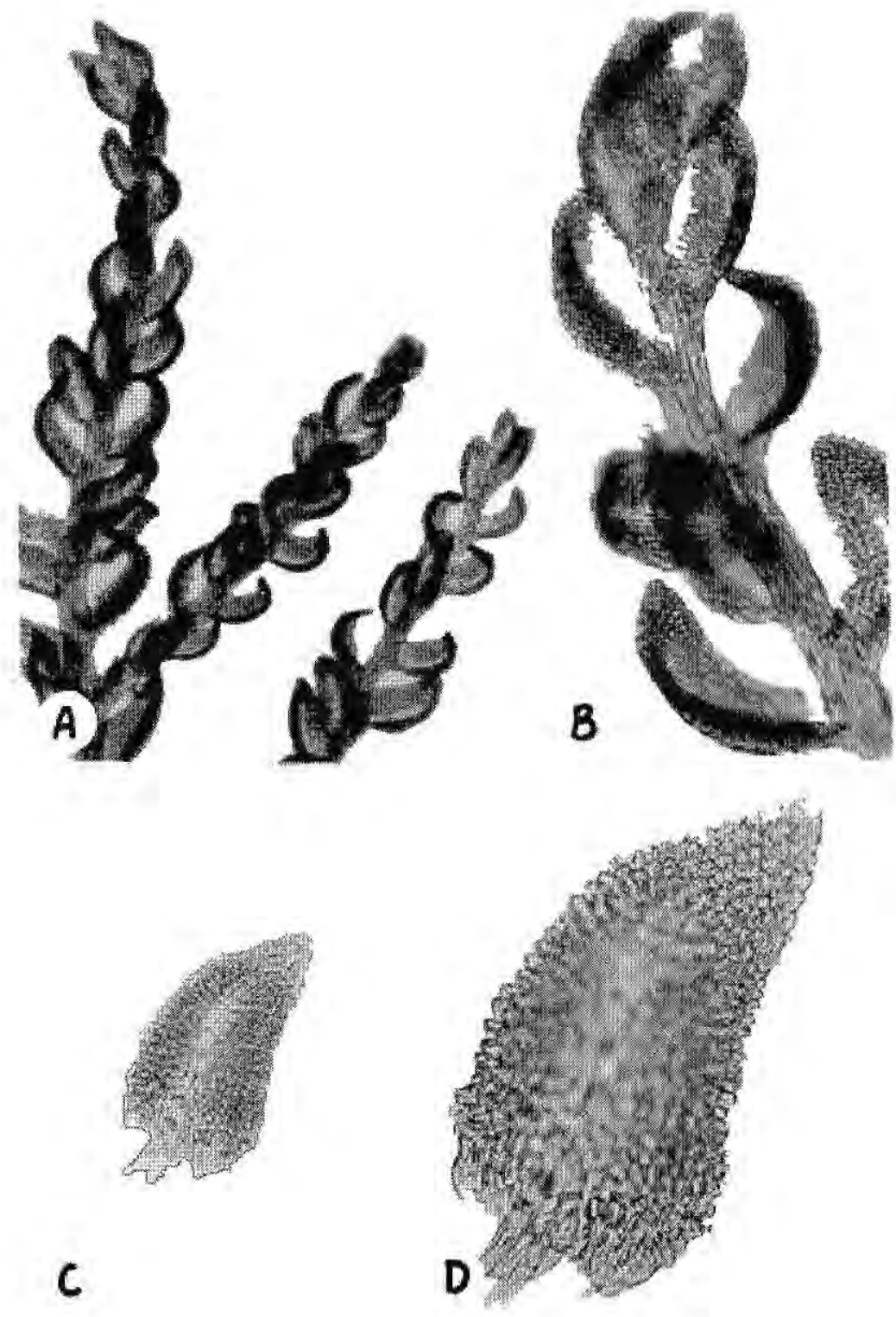

Figura 11. Cyrto-hypnum involvens. A) Detalhe dos ramos, 73X; B) Detalhe mais aumentado do anterior, 183X; C) Filidio inteiro, evidenciando concavidade na área desfocada, $183 \mathrm{X}$; D) Idem, 366X (A. L. Ilkiu-Borges, 15). 
(YANO, 1995) e para o Acre (VITAL \& VISNADI, 1994),

\section{DISCUSSÃO E CONCLUSÕES}

Os resultados apresentados neste trabalho confirmam LISBOA (1994), que ressaltou que à medida que fossem realizadas coletas e identificações no estado do Pará, a lista de novas ocorrências iria aumentar. Agora mais 11 espécies são acrescentadas. Destas, a mais abundante é Philonotis uncinata, coletada 30 vezes dentro da área urbana do município de Belém. $\mathrm{O}$ pequeno tamanho deste gênero deve ter adiado a inclusão da espécie na brioflora local.

Deve ser observado que a maioria das novas ocorrências aqui apresentadas são de espécies muito pequenas e de difícil identificação.

Thuidium involvens foi coletada 9 vezes, indicando uma boa freqüência, ocorrendo na área urbana de Belém e no Rio Iriri, municipio de Altamira.

Campylopus pilifer foi coletada 4 vezes na Serra dos Carajás apenas em vegetação de canga. As duas espécies de Taxithelium ocorrem na cidade de Belém, sendo que $T$. pluripunctatum também foi citada na Estação Cientifica Ferreira Penna e $T$. portoricense cresce também na Serra dos Carajás. Bryum apiculatum foi coletada apenas na área urbana. As demais espécies de Belém foram coletadas uma única vez, podendo ser consideradas raras no Estado do Pará, até o presente, já que o conhecimento insuficiente da brioflora da região Amazônica impede conclusão definitiva, como observado por LISBOA (1994).
No que se refere à distribuição geográfica das espécies, observa-se que Fissidens allenianus e Taxithelium portoricense são primeira referência para o Brasil; F. termitarum é referida pela primeira vez para a região Amazônica, o mesmo ocorrendo com Callicostella merkelii. Philonotis hastata havia sido referida apenas para Rondônia. Quanto às demais espécies, evidencia-se diminuição na área de disjunção.

\section{AGRADECIMENTOS}

A Dra. Olga Yano, pela ajuda na identificação de algumas espécies; ao Sr. Antônio Pinheiro, pela revelação das fotografias.

\section{Bibliografia citada}

BRUGGEMAN-NANNENGA, M.A; PURSELL, R.A. 1990. The Fissidens radicans Complex (Section Amblyothalia) in the Neotropics and Paleotropics. The Bryologist, 93(3):332-340.

BUCK, W.R. 1985. A Review of Taxithelium (Sematophyllaceae) in Brazil, Acta Amazonica., supl,, 15(1-2): 43-53.

COSTA, D. 1995. Musgos do municipio de Nova Friburgo, Rio de Janeiro, Brasil. Universidade de São Paulo, 326p. il. Tese de Mestrado.

CRUM, H. 1994. Taxithelitum. In: SHARP, A. J.; CRUM, H.; ECKEL, P. M. Eds. The Moss Flora of Mexico. Memoirs of the New York Botanical Garden, 69(Part two):1005-1006.

CRUM, H.; ANDERSON, L.E. 1981. Mosses of Eastern North America, vol. 1 e 2. New York, Columbia Univ. Press.

CRUM, H.; BUCK, W.R. 1994. Thuidiaceae. In: Sharp, A. J.; Crum, H. \& Eckel, P. M. Eds. The Moss Flora of Mexico. Memoirs of the New York Botanical Garden, 69 (Part two): 873-886.

FLORSCHÜTZ, P. A. 1964. The mosses of Suriname. Leiden, E.J.Brill. Part I, 271p. 
FLORSCHÜTZ-DE WAARD, J. 1986. Musci (Part II). In: A. L. Stoffers \& J.C. Lindeman. Ed. Flora of Suriname. Leiden, E.J.Brill, 6(1):273-361.

FRAHM, J. P. 1991. Dicranaceae: Campylopodioideae, Paraleucobryoideae. Flora Neotropica, 54:1-239.

GRIFFIN III, D. 1979. Guia preliminar para as briófitas freqüentes em Manaus e adjacências. Manaus, Acta Amazononica, 9(3):1-67.

GRIFFIN III, D. 1994. Bartramiaceae. In: SHARP, A. J.; CRUM, H. ECKEL, P. M. Eds. The Moss Flora of Mexico. Memoirs of the New York Botanical. Garden, 69 (Part one):537-574.

GRIFFIN III, D.; BUCK, W.R. 1989. Taxonomic and Phylogenetic Studies on the Bartramiaceae. The Bryologist, 92(3): 368-380.

LISBOA, R.C.L. 1991. Histórico da Briologia na Amazônia. Bol. Mus. Para. Emilio Goeldi, sér. Bot., 7(1):69-78.

LISBOA, R.C.L. 1993a. Musgos e Hepáticas. Ciência Hoje, Rio de Janeiro, 16(91):14-19.

LISBOA, R.C.L. 1993b. Musgos acrocárpicos do Estado de Rondônia. Belém, Museu Paraense Emilio Goeldi, 272p. il. Coleção Adolpho Ducke.

LISBOA, R.C.L. 1994. Adições à brioflora do Estado do Pará. Bol. Mus, Para. Emilio Goeldi, sér. Bot., Belém, 10(1):15-42.

LISBOA, R.C.L.; YANO, O . 1987. Novas ocorrências de briófitas na Amazônia brasileira. Bol. Mus. Para. Emilio Goeldi, sér. Bot., Belém, 3(2): 141-156.

OCHI, H.; SHOW, J.; CRUM, H. 1994. Bryaceae, In: SHARP, A . J. ; CRUM, H.; ECKEL, P.M. The Moss Flora of México. Memoirs of the New York Btoanical Garden, 69(Part one):452-529.
PŌRTO, K.C. 1990. Bryoflores d'une forêt de plaine et d'une forêt d'altitude moyenne dans l'État de Pernambuco (Brésil): Analyse floristique. Cryptogamie, Bryol. Lichénol., 11(2): 109-159.

PURSELL, R.A . 1994. Fissidentaceae. In: SHARP, A . J.; CRUM, H.; ECKEL, P.M. The Moss Flora of México. Memoirs of the New York Botanical Garden, 69 (Part one)::31-81.

PURSELL, R.A., BRUGGEMAN-NANNENGA, M.A.; IWATSUKI, Z. 1992. Species of Fissidens (Fissidentaceae, Musci) common to the Neotropics, Asia and África. Bryobrothera, 1: 49-55.

SYED, H. 1973. A taxonomic study of Bryum capillare Hedw, and related species. $J$. Bryol., 7: 265-326.

VITAL, D. M.; VISNADI, S. R, 1994. Bryophytes of Rio Branco Municipality, Acre, Brazil. Tropical Bryology, 9: 69-74.

YANO, O. 1981. A checklist of Brazilian mosses. J. Hattori Bot. Lab., 50: 279-456.

YANO, O. 1984. Checklist of Brazilian liverworts and hornworts. J. Hattori Bot. Lab., 56: 481-548.

YANO, O. 1989. An additional checklist of Brazilian bryophytes. J. Hattori Bot, Lab., 66: 371-434.

YANO, O. 1992. Novas localidades de musgos nos estados do Brasil. Acta Amazonica, 22(2): 197-218.

YANO, O. 1995. A new additional annotated checklist of Brazilian bryophytes. $J$. Hattori Bot. Lab., 78: 137-182.

YANO, O.; LISBOA, R.C.L. 1988. Briófitas do Território Federal do Amapá, Brasil. Bol. Mus. Para. Emilio Goeldi, sér. Bot., Belém, 4(2): 243-270. 